\title{
Evaluation of operation indicators of the working units of transporting devices made of polymeric materials
}

\author{
Maksim Moskovskiy ${ }^{1}$, Gaik Adamyan ${ }^{1, *}$, and Sergey Borzenko ${ }^{1}$ \\ ${ }^{1}$ Federal Scientific Agro-Engineering Center VIM, 1 Institutsky proezd, 5, Moscow, 109428, Russia
}

\begin{abstract}
In this paper we presents the results of production tests of a new transporting devices type made of with using new polymeric materials based on ultrahigh-molecular polyethylene (UHMWPE). It is possible to improve the operational properties of technological cleaning lines for grain seeds and improve the quality of grain cleaning.
\end{abstract}

\section{Introduction}

Post-harvest processing of seeds includes technological operations for cleaning, loading, unloading and transporting grain material. In addition, each operation affects the seed quality. Special requirements are connected with damage of the cleaned crops seeds.

Most researches have shown that most of the seeds are injured by transporting bodies. General injury of seeds are occurring during their post-harvest operations and it reaches $40-50 \%$ in some cases. Injury of seeds can reach the following values by working and transporting elements of production lines during their post-harvest treatment: wheat grain at the exit from the filling pit - from 5.0 to $13.7 \%$; in noria - from 4.0 to $12.0 \%$; in grain cleaning and sorting machines - from 2.0 to $8.4 \%[1,2]$. Considering that several receiving and transporting elements are used in modern technological lines, they injured significantly more seeds than working machines.

According this we introduce hypothesis that change of the type of material of the surface of contact with the grain and the kinetic modes of operation of the transporting bodies can reduce the impact of the main and auxiliary working bodies on the grain material, which will help to reduce its injury $[3,4]$.

\section{Materials and methods}

For research the process of transporting grain material and determination rational design, mode parameters, we designed construction of universal grain noria, the working bodies and elements made of a polymeric material ULTRA HIGH WEIGHT MOLECULAR

\footnotetext{
${ }^{*}$ Corresponding author: garikbegun@yandex.ru
} 
POLYETHYLENE (UHMWPE). It is made covering the shoe and the head of the noria with a polymer material based on UHMWPE. (thickness $\delta=2 \mathrm{~mm}$ ).

Modernization noria working bodies:

Polymer section. Feature of this section is the implementation of the "shaft" of polymer sheets, reinforced with metal ribs. Lightweight construction is a modular transforming type that provides different lifting heights. The design together with buckets of polymers provides "soft transportation". It contributes to the reduction of macro and micro injuries compared with those of metal, by 10-14\% (Figure 1).

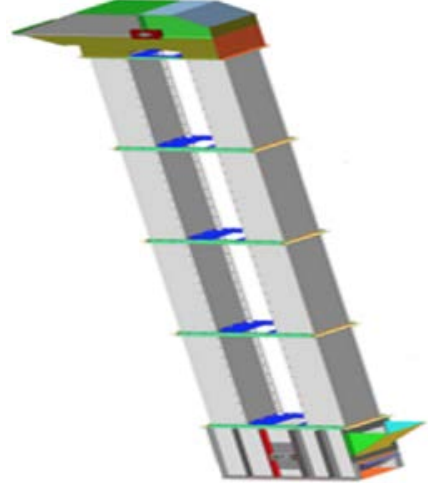

a)

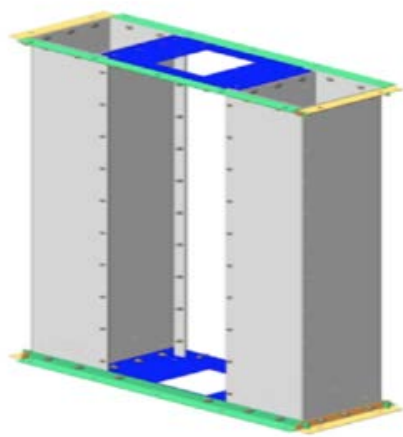

b)

Fig. 1. General view of noria :a) noria transformer combined by working bodies from polymeric materials based on UHMWPE. b) section of noria combined with a polymer material based on UHMWPE.

Shoe Noria. The lining of the noria shoe was carried out according to the dimensions shown in figure 3.a. It will contribute the reduction of the friction coefficient, impact processes on the grain material, the recovery coefficient of the grain. And it will also contribute to the reduction of macro and micro injuries by $25-30 \%$ in comparison with standard metal constructions of this class of conveyors (Figure 2).

Head of Noria. The geometry of the inner working surface of the head of the noria, together with the use of polymer coatings, reduces the impact processes occurring at the exit of the grain, which leads to a decrease in the injury of grain by $27-35 \%$.

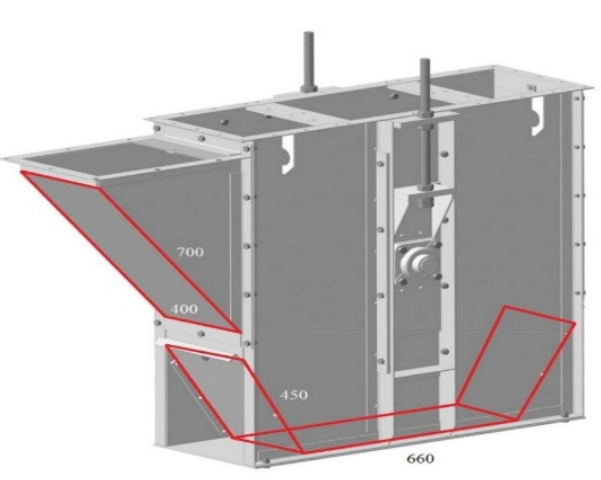

a)

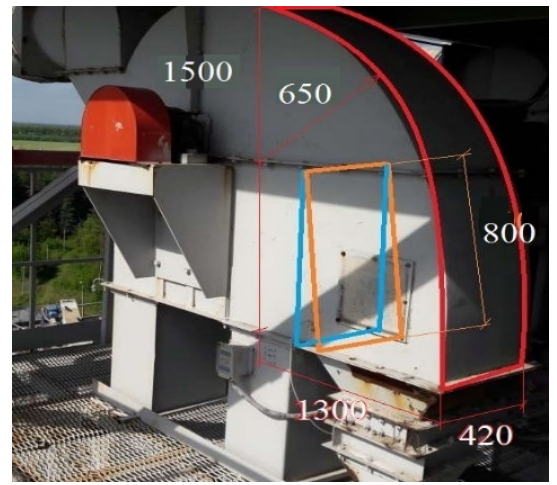

b)

Fig. 2. Design construction of noria: a) coating of the noria shoe with UHMWPE polymer, thickness $(2 \mathrm{~mm})$ with a total area of $1.85 \mathrm{~m}^{2}$, b) coating of the noria head with UHMWPE polymer with a thickness $(2 \mathrm{~mm})$ with a total area of $2,0 \mathrm{~m}^{2}$. 
Noria bucket. Ladle made of polymeric material, die casting method (Figure 3).

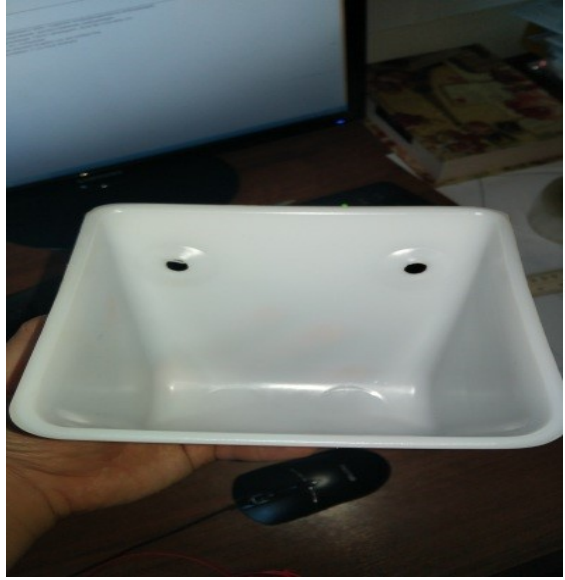

a)

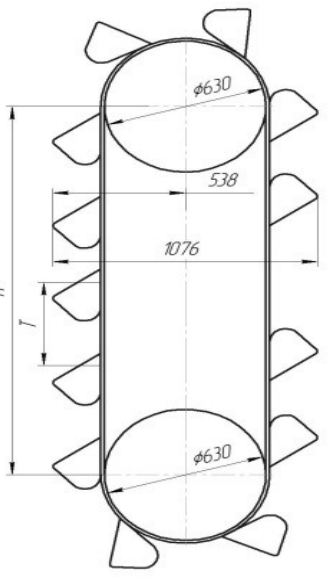

b)

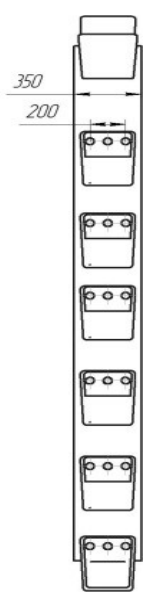

Fig. 3. Noria bucket: a) polymer bucket on the basis of UHMWPE material; b) method of its mounting on the tape.

\section{Results and discussions}

Production tests of noria were carried out during the harvesting season of 2016-2017. Noria worked on transporting grain cereals under various conditions as crops (different varieties of wheat and barley), yield, grain and straw moisture content, which mainly meet the requirements of specifications in the territory the existing agricultural enterprise, located in the Rostov region, Krasnosulinsky district, country Vladimirskoe. It was made plan and methodology for field research.

Comparative analysis of the yield seeds properties of winter wheat and barley (performed in 2016-2017) of the main indicators of quality is presented in table 1 and table 2 .

Table 1. The yield properties of winter wheat.

\begin{tabular}{|l|l|l|l|}
\hline Years & $\begin{array}{l}\text { Laboratory } \\
\text { germination, } \%\end{array}$ & Field germination, $\%$ & Grain yield, $t$ / ha \\
\hline Control (sampling from filling pit) & 529 \\
\hline $2016 \quad 96,2$ & 82,0 & 473 \\
\hline Injury of seeds on standard grain noria & 525 \\
\hline $2016-2017$ & 90,6 & 74,0 & \\
\hline \multicolumn{2}{|l|}{ Injury of seeds on the modernized grain noria } \\
\hline $2016-2017$ & 94,8 & 80,3 & \\
\hline
\end{tabular}

Table 2. Barley yield properties.

\begin{tabular}{|l|l|l|l|}
\hline Years & $\begin{array}{l}\text { Laboratory } \\
\text { germination, } \%\end{array}$ & Field germination, $\%$ & Grain yield, t/ ha \\
\hline Control (sampling from filling pit) & 95,9 & 87,5 & 55,1 \\
\hline 2016 & 81,3 & 49,6 \\
\hline Injury of seeds on standard grain noria & 54,7 \\
\hline $2016-2017$ & 90,2 & 86,4 & \\
\hline Injury of seeds on the modernized grain noria \\
\hline $2016-2017$ & 93,9 &
\end{tabular}




\section{Conclusions}

The modernization grain noria showed increasing in yield in 7-9\%, compared with analogs for 2016-2017, on the main crops of wheat and barley of the southern federal district. Field experiments of the detection yields changes are continuing.

Noria for the period of testing has worked flawlessly. It should be noted that the details made of UHMWPE polymeric materials showed the best characteristics under shock and abrasive loads. Time to failure noriya more than 8000 hours. The availability of operational time and taking into account the organizational time were equal to 0.99 and 0.987 , respectively. During the tests, no changes were made to the noria design.

\section{References}

1. Moskovskiy M. N. Thesis for the degree of Doctor of Technical Sciences: 05.20.01 / Kubansky State Agrarian University named I.T. Trubilina. Rostov-on-Don, 2017. Synthesis of system solutions for the technological process of obtaining seeds based on structural-functional modeling.

2. Pekhalsky I. A., Moskovskiy M. N. Reduction of seed injury by sieves. // Rural mechanization. 2015. №9. p. 22-23.

3. Moskovskiy M.N., Boyko A.A. Justification of the different schemes of cleaning the grain-cleaning unit, upon receipt of seed material in diversified agricultural production. // Don Engineering Engineer. 2013. №2. (25). p. 30.

4. Moskovskiy M.N., Grishkov A.D., Ignatenko V.I., Nemirovsky M.V. Method of calculating the soil-cutting working bodies made of tial-k polymer based on UHMWPE on the wear-resistance. // Natural and technical sciences. 2011. № 6. (56). p. 565-571.

5. Izmailov A.Yu., Moskovsky M.N., Podlesnyi D.S. Development of a set of working units from polymeric materials for the design of combine harvesters, International Conference on Modern Trends in Manufacturing Technologies and Equipment (ICMTMTE 2018) electronic edition. Cep. "MATEC Web of Conferences" 2018. C. 05010. 